\title{
O SENTIDO DE FILIAÇÃO TEÓRICA EM SUSPENSO NA CULTURA DA ESCRITA ACADÊMICA: DIÁLOGO ENTRE A ANTROPOLOGIA E A FILOSOFIA DA LINGUAGEM
}

\author{
THE MEANING OF THEORETICAL AFFILIATION IN \\ SUSPENSION IN ACADEMIC WRITING'S CULTURE: A DIALOGUE \\ BETWEEN ANTHROPOLOGY AND LANGUAGE PHILOSOPHY
}

\author{
Antonio Paulino de Sousa ${ }^{1}$ \\ Katia Cilene Ferreira França ${ }^{2}$ \\ Sulemi Fabiano Campos ${ }^{3}$
}

\begin{abstract}
RESUMO
Este trabalho tem como objetivo colocar em suspenso o véu da transparência que repousa sobre o sentido de filiação teórica na escrita acadêmica. Para essa problematização realizamos uma abordagem interdisciplinar ente a Antropologia e a Filosofia da Linguagem, particularmente, entre os estudos de Lévi-Strauss sobre o sistema elementar de parentesco e a família como átomo, que fala sobre as relações nos sistemas de parentesco, e os estudos de Bakhtin sobre o dialogismo e a genealogia dos enunciados, neste caso, a escrita que circula como conhecimento científico. Essa discussão ajuda a compreender a filiação teórica como uma atividade que não repousa na transparência e obviedade das normas que organizam as citações do discurso outro, ao contrário, ela está carregada de opacidade e de conflitos, há uma série de relações que entram em jogo no anúncio do pertencimento a uma família teórica. A discussão aqui proposta faz parte de nossa pesquisa de doutorado que tem como objeto de estudo a escrita acadêmica.
\end{abstract}

PALAVRAS-CHAVE: Filiação teórica; Escrita acadêmica

\begin{abstract}
This work aims to put in suspension the veil of transparency that rests on the meaning of theoretical affiliation in academic writing. For this problematization we carry out an interdisciplinary approach between Anthropology and Philosophy of Language, particularly between Lévi-Straus's studies on the elementary system of kinship and family as an atom, which talks about relations in kinship systems, and studies of Bakhtin on the dialogism and statements genealogy, in this case, writing that circulates as scientific knowledge. This discussion helps to understand theoretical affiliation as an activity that does not rest on transparency and truism of the norms that organize the quotations of the discourse other, on the contrary, it is loaded with opacity and conflicts, there are a series of relations that come into play in the announcement of belonging to a theoretical family. The discussion proposed here is part of our doctoral research that has as its study object the academic writing.
\end{abstract}

KEYWORDS: Theoretical affiliation; Academic writing

\footnotetext{
${ }^{1}$ Doutor em sociologia pela Université Paris Diderot e atualmente é professor titular da Universidade Federal do Maranhão. E-mail: antonio.paulino@terra.com.br

2 Doutora em Estudos da Linguagem, área de concentração em estudos da Linguística Teórica e Descritiva, pela Universidade Federal do Rio Grande do Norte. Atualmente é professora de Língua Portuguesa, do curso de Linguagens e Códigos, da UFMA- Campus São Bernardo. E-mail: katiacfranca@yahoo.com.br

3 Doutora em Linguística e Língua Portuguesa pela Universidade Estadual Paulista Júlio de Mesquita Filho. Atualmente é professora titular da UFRN. E-mail: sulemifabiano@yahoo.com.br
} 


\section{INTRODUÇÃO}

Filiação nos remete à relação entre pais e filhos, à ideia de família composta por vários membros, de uma relação de parentesco, que se constitui a partir de laços comuns, sejam eles biológicos ou não. Nesse sentido, a herança genética, observável por meio de exames, é uma prova da origem de um indivíduo, mas não é o único definidor da filiação, há os laços jurídicos e os afetivos que unem indivíduos na condição de pais e filhos, sem que haja entre eles qualquer relação de consanguinidade. Assim como famílias reconhecidas e que se reconhecem a partir de um conjunto de modos de proceder cultural, de um ethos que constitui e orienta a formação e a sobrevivência de grupos e tradições sobre a estrutura do parentesco.

A herança genética identifica os pais, quando se trata de consanguinidade; as certidões de adoção funcionam quando se trata de reconhecimento legal, mas nenhum desses sentidos pode ser explorado quando se trata da filiação teórica, mas é possível problematizá-la a partir de uma abordagem cultural. A produção de conhecimento científico acontece em meio a uma cultura acadêmica que possui regras próprias de funcionamento dentre as quais está o anúncio do lugar de enunciação, o reconhecimento de vozes já estabelecidas como representantes de linhas de pensamento, o gerenciamento dessas vozes para construção do próprio dizer, a compreensão de que em pesquisa ninguém é (ELIAS, 1998).

No sentido de desenvolver nosso ponto de vista cruzamos as fronteiras entre disciplinas e colocamos em diálogo a Antropologia e a Linguística, mais especificamente, os estudos antropológicos de Claude Lévi-Strauss e Alain Marie, sobre família e sistema de parentesco, e os estudos da filosofia da linguagem bakhtiniana, sobre a língua como atividade dialógica e o dizer constituído por uma genealogia. Duas disciplinas distintas, mas que têm em comum a concepção de que é preciso pensar na constituição das famílias e na genealogia indissociável das relações sociais e culturais. Esse cruzamento que aqui propomos foi o ponto de partida de construção do objeto de estudo nossa pesquisa construída ao longo do doutorado, de uma investigação sobre a filiação na escrita acadêmica. Este artigo, então, é parte da tese produzida.

O objetivo do presente texto é interrogar a concepção de que filiação teórica tem sentido transparente e dado. Costurando essa ilusão de transparência está a opacidade, está a heterogeneidade do dizer do sujeito que se faz pesquisador à medida que interage com o outro, com a cultura acadêmica e que busca ser reconhecido como representante dessa cultura.

Para alcançar esse objetivo, organizamos este artigo em três partes: a primeira voltada para o que diz a Antropologia Estrutural sobre a constituição de famílias e o sistema de parentesco; a segunda para as distintas configurações da filiação; a terceira para relação entre cultura acadêmica e filiação; a quarta para a filiação sob o viés da Filosofia da Linguagem.

\section{A família e a Antropologia Estrutural}

O que diferencia verdadeiramente o mundo humano do mundo animal é que, na humanidade, uma família não poderia existir sem existir a sociedade, isto é, uma pluralidade de famílias dispostas a reconhecer que existem outros laços para além dos consanguíneos e que o processo natural de descendência só pode levar-se a cabo através do processo social da afinidade (LÉVI-STRAUSS, 1982, p. 34).

Estudar a família para entender o que ela diz sobre a sociedade, esse é o investimento de Lévi-Strauss (1982). Sua proposta de estudo passa pelo deslocamento do sentido de família como um núcleo que se estabelece baseado apenas na consanguinidade, para a concepção de família como um átomo do sistema de parentesco, que agrega fatores biológicos e regras de organização social, ou seja, natureza e cultura entrelaçadas. Os laços que unem os parentes não têm o mesmo valor, os vínculos que ligam marido e mulher são diferentes daqueles que unem pais e filhos. A natureza, como diz Lévi-Strauss (1982), atribui a cada indivíduo determinantes genéticos herdados de seus pais biológicos, mas não decide quem serão esses pais, tal decisão depende das 
relações culturais, do jogo de interesse entre grupos sociais, que veem no casamento mais que a união de um casal, e na família mais que um núcleo formado por marido, mulher e filhos, isto é, veem a continuidade de uma cultura pela descendência e a preservação de tradições pela educação das novas gerações.

Considerando que continuar e preservar são pontos fundamentais para a sobrevivência de culturas e que as famílias têm o objetivo não apenas de gerar filhos, mas de transmitir-lhes as tradições, então o casamento, que institui a família, não acontece livre de regras que definem direitos e obrigações. A noção de regra é central na filosofia da linguagem e só pode ser pensada dentro de um sistema de relações (WITTGENSTEIN, 2001; BOUVERESSE, 1995).

Cada grupo tem regras próprias e precisa ceder, em alguma medida, para que a união se estabeleça, para que acordos entre diferentes sejam firmados e, dessa forma, alianças se efetivem. Casamento envolvendo diferentes grupos não se estabelece por vínculos afetivos entre homem e mulher, mas para responder a interesses dos grupos envolvidos, para dar continuidade à existência de uma comunidade e seu patrimônio cultural.

Em meio aos acordos, uma regra, como diz Lévi-Strauss (1982, p.70), aparece como ponto pacífico de preservação e transmissão aos descendentes: a proibição do incesto que "exprime a passagem do fato natural da consanguinidade ao fato cultural da aliança". Entre pais e filhos, irmãos e irmãs, em todas as culturas instituiu-se tal proibição, cuja justificativa principal é a preservação dos grupos, pois uma descendência fechada em si mesma sucumbe. A aliança entre grupos, então, torna-se uma questão de sobrevivência. Assim, marido e mulher unem culturalmente por um conjunto de direitos e obrigações, geram filhos, criam descendentes que carregam naturalmente a herança genética dos pais ao mesmo tempo em que aprendem, nas relações sociais com os grupos, as regras que precisam ser transmitidas e preservadas.

Tratar a proibição do incesto como uma regra cultural, redimensiona o sentido de família e coloca em suspenso a ideia de que essa proibição é espontânea, natural. Segundo Lévi-Strauss (1982, p.47), o que sustenta a ideia da proibição universal do incesto como algo natural, refere-se à perspectiva de que tudo o que é universal é governado pela ação da natureza e se caracteriza por uma espontaneidade, enquanto o que é da cultura se manifesta como normas e apresenta atributos relativos e particulares. $\mathrm{Na}$ contramão dessa ideia, o antropólogo aponta o que chama de escândalo, isto é, a proibição do incesto formada por duas características contraditórias e indissoluvelmente reunidas: ser uma regra, "mas uma regra que, única entre todas as regras sociais, possui ao mesmo tempo caráter de universalidade". Logo, infringi-la tem consequências que vão da reprovação generalizada à zombaria, há sempre um tipo de rejeição, e a penalidade depende não só da infração em si mesma, mas do modo como acontece e atinge o que é fundamental ao grupo.

Problemas comuns a todos são resolvidos por meio de intervenções, há uma espécie de conselho dentro do grupo, que atua para resolver situações que podem comprometer, de algum modo, a segurança ou algum outro tipo de fator de continuidade do grupo. A proibição do incesto é uma dessas ações. Segundo Lévi-Strauss (1982, p.71), trata-se de "a Intervenção", pois ela redefine o tipo de relação dos membros dentro de um mesmo grupo e de grupos diferentes entre si, institui a necessidade de alianças seladas por meio do matrimônio. O casamento sela acordos, define direitos e obrigações, dinamiza os arranjos familiares, garante renovação dos membros e amplia o sistema de parentesco.

Nesse sentido, troca e reciprocidade são as noções que movimentam as alianças e fundam as famílias. É preciso ter o que oferecer e o que receber, ou seja, não é apenas a natureza que define as condições pelas quais a família deve se constituir, as condições são também sociais e definidas nos termos do grupo, compatíveis com a vida coletiva. A família, segundo Lévi-Strauss (2012), é um átomo do parentesco, e deve ser vista não por seus problemas particulares, mas pelo que ela revela sobre o mundo social enquanto sistema de relações. 
Essa compreensão delineia-se quando se leva em conta a existência de diversos tipos de filiação determinados pela cultura e estabelecidos pelos laços matrimoniais, e ainda as configurações dos sistemas de parentesco, o papel desempenhado pelos membros.

\section{Distintas configurações da filiação}

Lévi-Strauss (1982) descreve diferentes organizações sociais e culturais, e explora as regras que orientam os casamentos em diferentes tribos, clãs, grupos espalhados pelo mundo, assim como, faz um levantamento sobre os tipos de filiação, considerando o modo como ela se constitui. Há a filiação: a) unilateral que se caracteriza por levar em conta apenas uma linha de descendência, seja ela materna ou paterna, ou seja, aos filhos só é legitimamente reconhecida a transmissão do parentesco de um dos pais; b) indiferenciada que funciona em oposição à unilinear, pois o parentesco é transmitido tanto pelo pai quanto pela mãe, isto é, há o reconhecimento das duas linhagens como aptas a transmitir direitos e obrigações; c) bilinear, própria dos sistemas rigorosamente definidos, em que duas linhagens unilineares se justapõem e cada uma transmite um certo tipo de direito e de obrigação aos descendentes.

Essas classificações não giram em torno apenas da relação marido e mulher ou pais e filhos, elas alcançam os variados membros que formam os sistemas de parentesco, pelo lugar que assumem, o modo como são nomeados e como se comportam na transmissão da cultura aos herdeiros.

Lévi-Strauss (2012) busca na Linguística o auxílio para compreender os termos de parentesco, não apenas em uma perspectiva sociológica, mas como elementos do discurso. Um dos pontos do diálogo com linguistas consiste em interrogá-los sobre as etimologias e fornecer a eles os costumes, as regras e as proibições, que permitem compreender a continuidade de certos traços de uma linhagem e a variação de termos. Esse cruzamento de fronteiras entres as disciplinas ajuda a organizar os termos de parentesco e descobrir seus significados.

As reflexões linguísticas desenvolvidas por Jakobson (1995) sobre a fonologia, especificamente sobre a pequena quantidade de sons que a língua retém diante de tantos sons disponíveis são importantes para a compreensão do sistema de parentesco, para o desenvolvimento de analogias. A pergunta de Jakobson sobre o porquê de certos sons serem selecionados e qual a relação entre os escolhidos e os demais tornou-se, nos estudos sobre o parentesco, às dúvidas: por que certos termos são escolhidos em relação a outros? Quais são as leis das combinações? (Lévi-Strauss, 2012). Essas ultimas interrogações exploram as relações de parentesco a partir de duas ordens: uma, chamada de sistema terminológico, que se refere aos termos que expressam distintos tipos de relações familiares; outra, chamada sistema de atitudes, voltada para os tipos de obrigações que os indivíduos sentem em relação aos outros e que lhes faz assumir um determinado comportamento, seja ele de direito ou de dever, de afeto ou de hostilidade.

O sistema terminológico engloba a descrição e a classificação de parentes paternos e maternos, sejam eles mais próximos ou mais afastados, identificados com uma palavra simples, ou designados por palavras compostas como é o caso de "irmão da mãe", ou "filho da irmã do pai", ou "filha da filha do pai". Essas expressões apontam para a cadeia de relações que une os indivíduos em vários graus, classificam parentes de gerações diferentes, tais como os primos paralelos (filhos ou filhas de um pai ou de uma mãe) ou os primos cruzados (filhos do irmão da mãe ou da irmã do pai). Há também os casos em que um mesmo termo é utilizado, indiferentemente, entre parentes de sexo diferentes. $\mathrm{Na}$ África, por exemplo, há grupos em que irmãos e irmãs da mãe são chamados de "mãe" e são reconhecidos por essa posição.

O sistema de atitudes diz respeito aos comportamentos socialmente prescritos, a atitudes codificadas, obrigatórias e validadas por tabus ou por privilégios. Entre alguns parentes, por exemplo, institui-se a familiaridade, até mesmo a troça; entre outros, a distância, a seriedade e o respeito. Em sociedades matrilineares, por exemplo, a relação entre o tio materno e seus 
sobrinhos, filhos de sua irmã, é de autoridade e de responsabilidades. Em outras palavras, o tio assume atitudes próprias de um pai na educação do sobrinho.

As diferenças quanto ao comportamento assumido por parentes mostram que a relação entre atitudes e nomenclatura não é uma correspondência exata. Segundo Lévi-Strauss (2012, p.68) “o sistema de atitudes constitui uma integração dinâmica do sistema terminológico". Logo, os termos de parentesco só adquirem significação integrados em sistemas. Essa característica vai ao encontro das pesquisas linguísticas que consideram a língua como um sistema no qual os termos não podem ser tratados como entidades independentes, uma vez que o seu valor está nas relações que eles estabelecem entre si.

Essa aproximação, no entanto, não guarda o caráter de universalidade alcançado pela Linguística ao tratar a língua como sistema de significação. Nas palavras de Lévi-Strauss (2012, p.68), "o sistema de parentesco é uma linguagem, não é uma linguagem universal", assim como as barreiras que separam e classificam as filiações não são estanques, isso porque todo sistema carrega consigo em alguma medida uma flexibilidade sobre o que deve ser transmitido e a quem cabe a missão de ensinar sobre os direitos e deveres a serem preservados.

Os tipos de filiação não se esgotam nos laços matrimoniais que se estabelecem por consanguinidade e afinidade, pelo encontro entre natureza e cultura, existem as filiações que acontecem segundo regras sociais, mas não passam por qualquer relação biológica na formação das famílias: são as filiações denominadas por Marie (1978) de mítica e fictícia.

Marie (1978) explora o sentido de filiação por três perspectivas: i) real, pautada em laços biológicos entre os parentes; ii) fictícia, que não envolve consanguinidade, mas no fato de as pessoas considerarem-se parentes; iii) mítica, que existe apenas na consciência dos homens e remete a antepassados comuns e muito distantes. A primeira apresentamos anteriormente a partir de Lévi-Strauss; importa-nos agora explorar os outros dois tipos elencados, os quais ajudam a entender os laços de parentesco que formam uma família teórica na escrita acadêmica.

A filiação fictícia acontece quando os indivíduos se consideram parentes e se comportam como tais (MARIE,1978). É o caso de descendentes de escravos ou prisioneiros de guerra que são vistos como filhos ou filhas da linhagem que comprou ou capturou os pais, ou ainda famílias estrangeiras acolhidas e depois de um longo tempo, de algumas gerações são assimiladas como parte do grupo de parentesco que as acolheu, a ponto de serem consideradas descendentes legítimos.

A filiação denominada mítica acontece no nível de uma consciência coletiva dos indivíduos e faz com que ocorra entre eles um certo tipo de comportamento comum e efetivo, movido pelos laços de solidariedade, de cooperação. Os indivíduos comportam-se segundo um conjunto de atitudes relativamente estáveis e institucionalizadas, que podem ser observadas e identificadas por quem está fora do sistema, pois se manifestam a partir de ações objetivas de uma linguagem comum utilizada não apenas pelos indivíduos de uma linhagem, mas por grupos diferentes ligados por um pensamento, uma concepção, uma crença coletiva.

Esse tipo de filiação, de acordo com Marie (1978, p.14), acontece quando os membros do grupo se assumem como pertencentes à linhagem de um antepassado mítico, ainda que não consigam traçar a linha genealógica que os liga a esse antepassado. É a crença na ligação a um ascendente comum que faz as linhagens se reconhecerem como parentes. Acontece também quando linhagens diferentes passam por reagrupamentos causados pela migração, os deslocamentos e a luta pela sobrevivência podem resultar na formação de um novo grupo heterogêneo em sua composição, mas uniforme em seu funcionamento, "variado aos olhos do observador, mas que se apresenta como o conjunto dos descendentes de um mesmo antepassado mítico".

As filiações fictícias e míticas ampliam a ideia de família, mostram que o parentesco é eminentemente uma relação social. Neste sentido, o sistema pode ser analisado como expressão direta das relações sociais, que acontecem entre os parentes, como uma metáfora dessas relações. É o caso dos vínculos políticos, que se formam de modo análogo àqueles que unem membros de 
uma família, e como um modo de formulação e interpretação ideológica, que oferece uma imagem das relações de trabalho, de produção e reprodução da vida material. Ou seja, há um feixe de relações que tornam o parentesco, segundo Marie (1978, p.20), não somente um princípio de classificação e organização dos grupos, mas também um código social, "uma linguagem mais ou menos ideológica e mais ou menos manipulada. É, pois, uma chave para interpretação de todas as sociedades".

Essa interpretação abre caminhos para que possamos entender a filiação teórica como uma atividade cultural e não como uma ação individual e independente, realizada pelo pesquisador, pois, se há família, há regras de organização, há direitos e deveres entre os membros, há traços comuns que lhes permitem duplamente se reconhecerem como parentes e ao mesmo tempo serem identificados por quem os observa de fora. É sobre essas regras de funcionamento que voltamos nossa atenção quando nos propomos a compreender a formação das famílias teóricas na cultura acadêmica (FRANÇA, 2018).

\section{Filiação e cultura acadêmica}

Em toda parte onde se manifesta uma regra podemos ter certeza de estar numa etapa da cultura (LÉVI-STRAUSS, 1982, p.47).

Família pressupõe, como vimos, uma relação social e um princípio de organização definido por regras culturais. A filiação teórica, como parte da cultura acadêmica, não é diferente, ao contrário, ela confirma e obedece a regras expostas e bem definidas ou veladas, mas presentes e atuando de modo eficiente na definição da família que faz uma pesquisa científica acontecer e aparecer como produção de conhecimento científico.

Manuais de metodologia da pesquisa, regras de submissão de trabalhos em eventos e periódicos científicos, para avaliação da qualidade da escrita acadêmica correspondem às regras expostas que marcam a existência de famílias e da cultura acadêmica. Esses instrumentos normativos tratam o sentido de filiação tanto como modo de informar sobre o local institucional ocupado por aquele que assina o trabalho, quanto de anunciar a linha de pensamento que fundamenta a pesquisa. Nos dois casos, a filiação funciona como um critério formal indicador de origem daquele que se colocar na condição de pesquisador.

A exposição do lugar de onde o sujeito enuncia ganha o sentido de pertencimento a pelo menos duas famílias interdependentes: uma ampla, que corresponde à instituição como um todo - como é o caso das universidades e tudo o que representam em termos de ensino, pesquisa e extensão - e uma restrita, que diz respeito à especificidade da investigação desenvolvida - como é o caso das teorias que compõem as disciplinas científicas ${ }^{4}$.

Esse anúncio é importante, mas insuficiente para mostrar ao observador os traços comuns entre a linguagem das famílias e aquela utilizada pelo pesquisador. É necessário que outras marcas apareçam e exponham a aprendizagem das regras ensinadas na convivência familiar que, no caso da filiação teórica, diz respeito às práticas de pesquisa, de leitura, de escrita com as quais o sujeito se envolve ao longo de sua formação como pesquisador, para tornar seu discurso coincidente com o das famílias, uma coincidência possível de ser identificada por quem observa.

Aprender essa linguagem comum exige tempo e envolvimento em vivências específicas, nas quais a escrita e a leitura têm um lugar privilegiado. O conhecimento científico, como diz Auroux (2008), não é acessível a todos, ele se caracteriza por uma forte codificação e pela dificuldade de aprendizagem. Há normas rigorosas a serem apropriadas e que devem ser reproduzidas, pois delas dependem a continuidade da cultura acadêmica. Ensinar práticas específicas é papel das universidades e se efetiva por meio de um conjunto de ações que

${ }^{4}$ Disciplina científica, neste caso, vai ao encontro da definição apresentada por Foucault (2007, p.30) em a Ordem do discurso, quando diz que disciplina se define por um domínio de objeto, um conjunto de métodos, um corpus de proposições consideradas verdadeiras, um jogo de regras e definições, de técnicas e instrumentos. 
envolvem aulas, exames, assim como pela formação de grupos empenhados em desenvolver estudos sobre uma linha teórica.

Nesses grupos, as práticas de leitura e escritas são reforçadas, lapidadas e ao mesmo tempo delimitadas. Os membros cooperam entre si, ajudam-se no processo de ensino e aprendizagem da teoria a que o grupo se dedica, na compreensão das regras do discurso científico, na assunção de uma posição teórica e, consequentemente, na delimitação de um conjunto de autores que representam a filiação do pesquisador. Em meio a esse conjunto de autores estão nomes vivos e próximos dos grupos, outros separados por uma distância temporal, mas que se fazem presentes e atuais pois são tratados como ponto de partida para a debates, construção de objetos de estudo.

O papel dos grupos na disseminação e fortalecimento da ciência é real. Kuhn (2013, p.53), ao tratar sobre as revoluções científicas, apresenta o conceito de paradigma como "realizações científicas universalmente reconhecidas, que durante algum tempo forneceram problemas e soluções modelares para uma comunidade de praticantes de uma ciência", aponta que essas realizações são divulgadas e ensinadas como modelos rigorosos para a resolução de problemas de pesquisa. Aprender e aplicar, no entanto, não é suficiente para produzir novos paradigmas, e sim para a definição de uma ciência normal (KUHN, 2013), ou seja, uma ciência em que o empreendimento do cientista não está em trazer à tona novos fenômenos, inventar teorias.

Esse empreendimento não é uma atividade isolada do pesquisador, ela se consolida nos grupos, nas comunidades científicas que atuam no sentido de ensinar aos membros sobre as realizações científicas de validade universal, de treiná-los para a aplicação rigorosa de um paradigma. Sobre o treinamento, pode-se dizer que quanto mais dogmático for, mais coerentes serão as respostas dos aprendizes, mais eficaz será a comunicação científica. O efeito dessa ação pedagógica promove a integração cognitiva do grupo, a ponto de os membros considerarem-se pertencentes a uma família teórica. Nas palavras de Kuhn (2013, p.282)

A maioria dos cientistas responde imediatamente a perguntas sobre suas filiações comunitárias, certos de que a responsabilidade pelas várias especialidades atuais está distribuída em grupos com um número de membros pelo menos aproximadamente determinado.

Essas filiações comunitárias fazem com que membros do grupo vejam a si mesmos e sejam vistos como guardiões de um conhecimento que precisa ser preservado e conservado. Os membros devem assumir a responsabilidade de treinar sucessores, gerar herdeiros capazes de continuar o legado da família.

Hagstrom (1965) trata esses grupos como comunidades que se organizam dentro de um sistema de trocas entre o cientista e a instituição científica. Em sua abordagem, os grupos são integrados não apenas como resultado da socialização do pesquisador em seu processo formativo, como um desejo de saber, mas especialmente como busca por legitimidade no meio científico. $\mathrm{O}$ autor defende que a ciência possui um controle social interno, um conjunto de normas e valores ao qual o pesquisador precisa adequar-se. A relação entre o pesquisador e a comunidade científica se dá da seguinte forma: o primeiro produz informação pública, enquanto a segunda lhe confere reconhecimento e prestígio. Nesse mercado de trocas, publicar torna-se moeda de valor, especialmente em revistas científicas que são ao mesmo tempo fonte de reconhecimento operam como fonte de controle do conhecimento científico.

As perspectivas de Kuhn e de Hagstrom mostram que a relação entre a instituição e os grupos é de interdependência. A produção científica é resultado da ação dos grupos que fazem a cultura acadêmica continuar e se diferenciar entre as demais, ao mesmo tempo em que a instituição que lhes garante existência. Seja por deixar sucessores de uma linha teórica, seja por produzir e publicar, os grupos estão sempre atuando para formar descendentes da cultura que os origina, ensinando-os a responder adequadamente sobre sua filiação institucional e teórica, bem 
como a utilizar uma linguagem que os una como família e ao mesmo tempo os diferencie de outros grupos (FRANÇA, 2018).

Uma família teórica solicita uma referência, pais em torno dos quais as relações de filiação acontecem. O lugar de pai, na cultura acadêmica, não é atribuído pelo próprio pesquisador, mas pela instituição, que define o nome próprio, o cientista que alcançou a posição de referência pelas contribuições novas e originais sobre e para a produção de conhecimento científico, pelos diálogos que estabeleceu com antepassados da cultura acadêmica. Ser considerado pai, iniciador de uma família, é alcançar um título de muito prestígio.

Uma retomada a nome de pais na cultura acadêmica nos encaminha a Galileu Galilei, matemático, físico e astrônomo, que no século XVI-XVII, elabora teorias as quais ainda hoje motivam outras descobertas. Outra regressão nos leva a Ferdinand Saussure linguista que, no século XIX, delimita o objeto de estudo da Linguística e continua sendo ponto de partida para novos trabalhos. Dois autores, considerados revolucionários por criarem paradigmas (KUHN, 2013) e tratados como fundadores por terem produzido possibilidades e regras para formação de outros textos. Galileu Galilei e Saussure recebem o título de pais por criarem métodos, elaborarem discursos nonsense. Eles se apropriam das regras que fazem funcionar o discurso científico em uma ordem institucional, subvertem-no e produzem novidades. A subversão foi absorvida pela academia, legitimada a ponto de torná-los pais teóricos, em torno dos quais famílias podem formar-se e desenvolver-se.

No entanto, nem só como fundadores de disciplinas científicas ${ }^{5}$ nascem os pais. Há os descendentes extremamente empenhados em continuar e aprofundar as ideias dos pais, aplicá-las e relacioná-las com estudos vindos de outras teorias. Nesse processo, a publicação ganha destaque, pois a partir dela o descendente pode ganhar notoriedade a ponto de receber um tratamento similar ao do pai considerado fundador, de modo a figurar nos artigos não como parte do conjunto de autores convocados para fundamentar teoricamente o trabalho, mas como o autor referência em meio a todos os outros convocados na pesquisa. Ou seja, o sentido de pai não é exato, nem os descendentes são uma reprodução em série de pesquisadores, ele se altera porque é uma construção social e, como tal, motivada e controlada por uma série de fatores ligados ao objeto de estudo e a pressões e seduções da cultura da instituição. Uma delas é tratar a citação como instrumento de medida de qualidade da pesquisa, fato que interfere na delimitação de quais vozes convocar, que nomes vão ficar marcados como fundamentação da pesquisa.

Nesse sentido, fazer uso do discurso alheio, delimitar e citar um autor como a principal referência, como uma espécie de pai teórico do pesquisador em formação, é uma atitude que nos faz pensar não apenas sobre questões epistemológicas para formulação de um objeto, mas também sobre os instrumentos que avaliam o valor do trabalho, da família teórica a partir de dados estatísticos. Uma discussão sobre tais instrumentos é levantada por Gringas (2016), a partir de uma retrospectiva sobre os sentidos que a bibliometria ganha ao longo do tempo.

Gringas (2016) conta que a bibliometria surge com objetivo de fazer a gestão da literatura científica, de fornecer um sistema de indexação para facilitar o acesso a trabalhos ligados ao objeto de estudo do pesquisador. Ao longo da história, a bibliometria ganha outras funções relacionadas a práticas de publicação, a ponto de tornar-se um procedimento administrativo de avaliação e gestão da carreira universitária. A consequência de tais mudanças pode ser observada nas publicações científicas, nas citações. É preciso citar e ser citado para alcançar uma performance

\footnotetext{
${ }^{5}$ Foucault (2007) diz que a organização das disciplinas se opõe a dois princípios: do autor e do comentário. Ao autor porque o sentido ou a validade de uma disciplina não está ligada ao nome de um inventor, mas a um conjunto de métodos, a delimitação de um objeto, a técnica, a um sistema anônimo à disposição de quem quiser se servir. Ao princípio do comentário porque a disciplina se caracteriza por oferecer a possiblidade de criação de proposições, precisa fomentar indefinidos enunciados, enquanto o comentário é uma forma de repetição e de dizer mesmo, um princípio a partir do qual é possível construir um dizer, mas essa construção é limitada e restrita. Essa oposição não é, no entanto, um ponto que vamos explorar neste trabalho, pois não buscamos entender como se dá a constituição de uma disciplina no sentido foucaultiano, mas entender a filiação teórica que tanto pode aparecer ligada a pais fundadores de disciplinas ou não. Comentadores também podem ser assumir a posição de pais.
} 
produtiva, para que pesquisas sejam aprovadas, projetos recebam recursos e revistas sejam classificadas como produção científica legítima.

Nesse sentido, o investimento do pesquisador, para ser reconhecido como parte de uma família, torna-se indissociável da obrigação de citar a palavra alheia e nomeá-la, ou seja, atuar como um multiplicador da cultura que o precede. A família espera e cobra essa atitude de seus membros, que as vozes sejam multiplicadas na defesa de uma concepção de pesquisa e de compreensão dos acontecimentos. Essa estratégia de aferir a produção pela quantidade esconde a convenção de equivalência ${ }^{6}$ entre os membros de uma comissão avaliadora atrás da objetividade dos números. Nessa perspectiva, diz Sousa (2017), a quantidade de citação torna-se requisito para julgamento, geram-se carteis de citações, inférteis sob o ponto de vista da qualidade da pesquisa, mas eficientes em classificar e ranquear investigadores e instituições.

É em meio a um feixe de relações que a filiação teórica se forma, ela não nasce como se fosse uma força natural, mas como uma construção própria da cultura acadêmica, que guarda características do que Marie (1978) apontou como sendo filiação fictícia e mítica, uma vez que se estabelece pelo sentido de pertencimento a uma família que acolhe novos membros e oferece-lhe direitos e obrigações, ensina a crença de que existe um eficaz conjunto de normas, o qual deve ser seguido para que um discurso seja reconhecido pela instituição como científico, ainda que a origem dessas normas não seja clara nem precisa aos seguidores.

Os laços que estabelecem a filiação teórica guardam uma complexidade que passa pelo funcionamento das instituições científicas, mas não se esgota nesse aspecto. Como diz Maingueneau (1997, p.58), o trabalho de interpretação da sociologia da produção científica busca entender como a instituição trabalha para se manter a partir de sua produção, mas não analisa essa produção a partir da dimensão textual. Esse silêncio abre espaços para uma investigação sobre a filiação teórica na escrita acadêmica, enquanto atividade responsiva (BAKHTIN/VOLOCHINOV, 2006) permeada de sentidos sobre os diálogos que o sujeito realiza para condição de pesquisador.

\section{Filiação e filosofia da linguagem bakhtiniana}

A língua passa a integrar a vida através de enunciados concretos (que a realizam); igualmente através de enunciados concretos que a vida entra na língua. O enunciado é um núcleo problemático de importância excepcional (BAKHTIN, 2003, p.265).

A ideia de enunciado como ponto de encontro entre a língua e a vida é a concepção que fundamenta a nossa busca por entender a constituição da filiação teórica na escrita acadêmica. Em outras palavras, compreende olhar para essa escrita como uma produção dependente de um contexto, das condições de comunicação em que acontece, e da posição social ocupada pelos interlocutores, significa tratar os enunciados não como frases que se reproduzem indefinidamente com os mesmos significados, mas como enunciados que respondem a condições e finalidades específicas que os tornam únicos e particulares, ao mesmo tempo que lhes imprime como ponto comum o fato de que cada enunciado é parte de um diálogo iniciado antes. Cada enunciado é para Bakhtin (2003), um elo da cadeia da comunicação verbal, é parte de um grande e ininterrupto diálogo.

O ponto de vista bakhtiniano defende a concepção de língua constituída por signos móveis e vivos, a qual não é adquirida como produto acabado, mas aprendida a partir das

\footnotetext{
6 A noção de convenção das equivalências é importante para a emergência de uma antropologia crítica da quantificação. O interesse desta noção é que ela combina uma noção social das convenções e uma noção lógica, a de equivalência. É preciso se reunir para conviver com o que é equivalente, isto significa que a equivalência não é imediatamente dada, ela é construída na negociação entre atores sociais. Esta ideia introduz uma ruptura com a concepção positivista das ciências sociais quantitativas ao pôr um fim à naturalização das categorias sociais oriundas da estatística. (DESROSIÈRES, 1993, 2014).
} 
interações que o sujeito realiza, de suas experiências e sua imersão no grande e inconcluso fluxo da comunicação. O mergulho proporciona o despertar da consciência para a compreensão e produção de enunciados enquanto respostas ativas, individuais, mas nunca isoladas. O diálogo com os já ditos que são essenciais e ficam impressos, deixam à mostra e deixam à mostra sentidos e valores que não partem do sujeito, este apenas lhes dá continuidade, uma vez que se encontra ligado a tais valores e sentidos por laços genealógicos, que não podem ser negados sob pena de o sujeito negar a si mesmo. Nas palavras de Bakhtin (2003, p.164), "Minha linhagem (ou meu pai, minha mãe) tem valor não por me pertencer, isto é, não sou eu que a torno valorativa (não é ela que se torna um elemento do meu ser axiológico), mas por eu pertencer a ela".

A genealogia de que trata Bakhtin (2003) não possui a significação restrita de atividade marcada pela presença de indicações nominais sobre uma origem, pois a filiação se mostra por formas sutis que envolvem a maneira de dizer, as palavras selecionadas, e o valor que o sujeito atribui a elas. $\mathrm{O}$ interlocutor percebe essas sutilezas e reage a elas, responde segundo sua compreensão. Dizer que há uma relação de filiação orientando um dizer não significa negar a capacidade inventiva do sujeito, ao contrário, a genealogia é fundamental para a produção de novos enunciados.

Os dicionários, por exemplo, registram significados socialmente pactuados e imprescindíveis no processo de transmissão, aquisição e continuidade da língua. Aliada aos significados estabelecidos está a criatividade como condição de existência dos enunciados. $\mathrm{O}$ ato de criar acontece porque os diálogos não se estabelecem pelo uso de palavras soltas, mas de arranjos entre elas e das negociações de sentidos entre os falantes. A cada enunciado elaborado, a dupla paradoxal dimensão da língua se manifesta: o dado e o criado (BAKHTIN, 2003). Para criar, é preciso partir do que foi assimilado, compreendido pelo sujeito a partir dos diálogos que estabeleceu, de sua vida social.

A relação entre o dado e o criado é de transformação, reconstrução pelo diálogo em direção à alteridade. A complexidade dessa relação está no fato de o sujeito compreender a palavra alheia e torná-la própria, a ponto de sentir-se dono de seu dizer, de separar suas palavras das palavras do outro, de tornar a palavra alheia em palavra própria, de desconsiderar que os limites entre as palavras são instáveis, que entre o dado e o criado as barreiras são flutuantes e nelas, diz Bakhtin (2003, p.380), "desenvolve-se uma tensa luta dialógica", que ressoam as vozes da genealogia. $\mathrm{Na}$ luta os laços familiares são expostos tanto pelo modo como os enunciados são elaborados e pelo conteúdo temático que carregam.

A escrita de uma pesquisa representa bem a luta tensa e dialógica provocada pela instabilidade das barreiras entre a palavra própria e a palavra do outro, mostra como a genealogia ressoa a partir da relação com os já ditos anunciados na materialidade da escrita. Os recursos da língua põem à mostra a busca do sujeito em traçar limites entre as diferentes vozes que ele convoca para construir seu dizer, para se fazer aparecer a partir de uma linha(gem) teórica, e ao mesmo tempo não ser sufocado pela própria filiação. Nesse sentido, o diálogo com o outro é constantemente anunciado, identificado por recursos como as aspas e as indicações nominais, com o objetivo de mostrar àquele que lê a palavra do outro enredada à palavra própria, funcionando como suporte para a elaboração de um novo dizer.

No entanto, apenas o uso desses recursos não basta para resolver o problema das fronteiras entre as palavras: as aspas e as outras formas de transmissão e delimitação do discurso de outrem, no próprio discurso, carregam a presença do eu, uma vez que são um recorte feito pelo sujeito a partir de sua compreensão. Do mesmo modo, as relações que o sujeito estabelece, as conclusões a que chega ao longo de sua pesquisa, o uso de pronomes e verbos em primeira pessoa, indicadores da palavra própria do sujeito, também não estão livres da presença da palavra alheia. Ao contrário, elas retomam os já ditos em diferentes níveis de concordância ou discordância. Ou seja, "um enunciado absolutamente neutro é impossível" (BAKHTIN, 2003, p.289), no entanto, esse fato não impede que se possa analisar a relação entre o discurso de outrem no próprio discurso a partir de recursos da língua, que se possa verificar o modo com a 
palavra alheia é compreendida e transmitida para a construção de um dizer próprio e ligado a uma genealogia.

O jogo que entre a palavra do sujeito e a palavra alheia podem ser observados, segundo Bakhtin/Volochinov (2006) a partir de esquemas linguísticos analisados como problemas de ordem sintática. Os esquemas permitem: observar o problema das fronteiras entre as palavras a partir de uma análise sociológica em linguística; verificar como os recursos da língua funcionam como sinal de alteridade; ver que a relação entre os interlocutores é constitutivamente atravessada por um terceiro personagem que se situa acima do falante e do ouvinte e atua dando consistência e vigiando a produção dos enunciados. Esse terceiro é o supradestinatário, explicado por Bakhtin (2003) como um conjunto de valores que se revela de maneiras variadas, ao longo do tempo, por meio distintas expressões ideológicas como Deus, povo, voz da ciência, voz da instituição acadêmica.

A instituição, como supradestinatário na escrita acadêmica, vigia as produções a partir de seus próprios membros, daqueles que aprenderam que não é possível dizer tudo o que se quer e do modo que se quer, que é preciso produzir enunciados adequados às regras da instituição, dentre as quais está a compreensão de que em enunciados científicos as palavras circulam como conceitos teóricos, como uma ideia desenvolvida a partir de problematizações realizadas por cientistas específicos (FOUCAULT, 2007).

Diferentemente dos verbetes dicionarizados que não têm sua significação ligada ao nome de um criador e são apresentadas como resultado de um consenso coletivo sobre o sentido, como um significado que pertence a todos, as palavras que circulam como conceitos científicos estão sempre ligadas ao nome de alguém na condição de fundador de um sentido, e a um conjunto de pesquisadores que se unem com a finalidade de compreender a construção conceitual, de aplicá-la e fazer referência ao nome daquele que a inaugurou.

O nome do fundador, como diz Foucault (2009), assume uma função classificativa, e em relação a ele, textos se agrupam, são delimitados e confrontados. O conceito funciona como um dado - composto de uma dimensão teórico-metodológica - a partir do qual o pesquisador deve criar, uma criação cercada de cuidados sobre a lida com a palavra alheia portadora de autoridade científica. Uma lida fundamental para quem se coloca como filiado na cultura acadêmica.

\section{CONSIDERAÇÕES FINAIS}

O jogo que envolve a citação do nome e da palavra do outro mostra que não é possível fazer a travessia do dado para o criado sem que a filiação venha à tona e fique exposta, sem que faça um rastro na materialidade da escrita acadêmica. Esses rastros não consistem em um caminho pronto, mas em indícios de como a filiação foi construída, da presença de uma genealogia enquanto atitude de pesquisa, na qual nomes próprios não figuram com funções exatas, mas como membros de uma família que fala antes do pesquisador e da qual ele que fazer parte.

Considerando que o sujeito não é senhor de seu dizer, não se pode defender a ideia de que a definição da genealogia, a delimitação de vozes e a atribuição do lugar a ser ocupado por cada uma na escrita, se configura como uma escolha autônoma. A autonomia é relativa e vinculada a uma série de pressões, especialmente quando se trata de pesquisadores em formação, que precisam considerar a interferência do professor-orientador e a avaliação da banca. Nesse sentido, olhar para a escrita acadêmica a fim de compreender a filiação demanda uma série de relações e todas passam por um ponto comum: a relação dialógica com o outro.

O outro se faz sempre presente de diferentes maneiras e pode ser sempre verificado a partir da materialidade da língua, nem mesmo o supradestinatário escapa. Uma observação atenta para o enunciado desvela esse outro que se configura como um conjunto de valores sociais, como expressão ideológica. Verificar e analisar a presença do outro na escrita acadêmica é algo possível porque, como diz Bakhtin/Volochinov (2006), a natureza dos enunciados é social, porque as 
formas de transmissão da palavra alheia não mostram apenas conteúdo temático, mas a reação ativa de uma enunciação na outra, mostram como o discurso de outrem entra no dizer do sujeito e a ele se integra.

$\mathrm{Na}$ escrita acadêmica, as lutas do sujeito voltam-se para a palavra alheia carregada de autoridade científica. A filiação precisa ficar à mostra, as vozes são convocadas, identificadas e dispostas segundo o nível de importância no trabalho. A maneira como as vozes são colocadas umas em relação às outras diz sobre o papel que cada uma assume, há aquelas que são tratadas como referência pois fundamentam o problema construído pelo pesquisador, mas há também aquelas citadas porque comentam autores que são referência; há as vozes convocadas pelos estudos que desenvolveram e pelos conceitos que construíram, citá-los é uma obrigação.

Com base no viés antropológico, é possível dizer que a filiação teórica guarda características da filiação fictícia e mítica, que acontece independente dos laços genéticos e completamente motivada por laços culturais, especificamente da cultura acadêmica. $\mathrm{Na}$ escrita de uma pesquisa, imprimem-se relações de parentesco, há uma regularidade nos modos como as famílias vão se formando, o que permite ao observador identificar os membros e verificar o lugar que eles ocupam, o papel que desempenham uns em relação aos outros. Permite-lhe, também, perceber as alianças entre teorias que fazem nascer as famílias, os pais teóricos dos quais as pesquisas descendem.

$\mathrm{Na}$ dinâmica da escrita acadêmica acontece um encontro de vozes, regulado pela compreensão do sujeito. Citar então significa não apenas recortar e colar a palavra alheia, mas falar dessas vozes, dialogar com elas e a partir delas construir o próprio dizer enquanto membro de uma família que está inserida na cultura acadêmica.

\section{REFERÊNCIAS}

AUROUX, S. A questão sobre a origem das línguas seguido de $\mathbf{A}$ historicidade das ciências. Trad. Mariângela Pecciolli Gali Joanilho. Campinas, SP: Editora RG, 2008.

BAKHTIN, M. Os gêneros do discurso. In: Estética da criação verbal. $4^{\mathrm{a}} \mathrm{ed}$. Trad. Paulo Bezerra. São Paulo: Martins Fontes, 2003, p.261-306.

BAKHTIN, M. O todo semântico da personagem. In: ed. Trad. Paulo Bezerra. São Paulo: Martins Fontes, 2003, p.127-171.

Estética da criação verbal. $4^{\mathrm{a}}$

BAKHTIN, M. Apontamentos de 1970-1971. In: Estética da criação verbal. $4^{a}$ ed. Trad. Paulo Bezerra. São Paulo: Martins Fontes, 2003, p.367-392.

BAKTHIN, M. [VOLOCHINOV, V. N.]. Marxismo e filosofia da linguagem. 12. ed. Trad. Michel Lahud e Yara Frateschi Vieira, com a colaboração de Lúcia Teixeira Wisnik e Carlos Henrique D. Chagas Cruz.São Paulo: HUCITEC, 2006, 203p.

BOUVERESSE, J. Régles, dispositions et habitus. Revue Critique, Paris, v.51. n 579-580, 1995, p.573-594.

DESROSIÈRES, A. La politique des grands nombres. Histoire de la raison statistique. Paris : La Découverte, 1993.

DESROSIÈRES, A. Pouvoir et gouverner. Une analyse polítique des statistiques publiques. Paris : La découverte, 2014.

ELIAS, N. Envolvimento e alienação. Rio de Janeiro: Bertrand Brasil, 1998. 
FRANÇA, K. C. F. A filiação teórica na escrita do pesquisador em formação: uma análise sobre a genealogia do dizer acadêmico pelas formas da língua. 2018.

FOUCAUlT, M. A ordem do discurso. 15ªed. Trad. Laura Fraga de Almeida Sampaio. São Paulo: Edições Loyola, 2007.

GINGRAS, Y. Os desvios da avaliação da pesquisa: o bom uso da bibliometria. Trad. Carlos Deanne. Rio de Janeiro: Editora UFRJ, 2016.

HAGSTROM, W. O. The scientific community. New York: Basic Books, 1965.

JAKOBSON, R. Lingüística e comunicação. Trad. Izidoro Blikstein e José Paulo Paes. São Paulo: Cultrix, 1995.

KUHN, T. S. A estrutura das revoluções científicas. 12. ed. Trad. Beatriz Vianna Boeira e Nelson Boeira. São Paulo: Perspectiva, 2013.

LÉVI-STRAUSS. C. A família. In: SHAPIRO, Hanry L. (Org.). Homem, Cultura e Sociedade. 2. ed. Trad. Robert Coaracy e Joanna E. Coaracy. Rio de Janeiro: Fundo de Cultura, 1972, p. 7-45.

LÉVI-STRAUSS. C. Antropologia estrutural. Trad. Beatriz Perrone-Moisés. São Paulo: Cosac Naify, 2012.

LÉVI-STRAUSS. C. As Estruturas elementares do parentesco. Trad. Mariano Ferreira. Petrópolis: Vozes. 1982.

MAINGUENEAU, D. Novas tendências em análise do discurso. $3^{\mathrm{a}}$ ed. Trad. Freda Indursky: revisão dos originais da tradução Solange Maria Ledda Gallo, Maria da Gloria de Deus Vieira de Moraes. Campinas, SP: Pontes, 1997.

MARIE, A. Introdução ao Vocabulário do Parentesco. In: AUGÉ, Marc (Dir.) Os domínios do parentesco: filiação, aliança matrimonia, residência. Trad. Ana Maria Bessa. Lisboa: Edições 70 (col. Perspectivas do Homem, n. . 2), 1978, p.11-74.

SOUSA, A. P. de. Gingras, Yves (2014), Lesdérives de l'évaluation de larecherche. Du bom soususage de labibliométrie. Revista Crítica de Ciências Sociais[Online], 113 | 2017, p.176179. Disponível em: <http://rccs.revues.org/6715>. Acesso em: 30 de agosto de 2017.

WITTGENSTEIN, L. Philosophical investigations. Oxford: Blackell, 2001.

Submetido em 22/12/2019

Aceito em 10/01/2020

Publicado em 14/01/2020 